\title{
Inundation and groundwater dynamics for quantification of evaporative water loss in tropical wetlands
}

\author{
J. Schwerdtfeger ${ }^{1}$, M. S. Johnson ${ }^{2}$, E. G. Couto ${ }^{3}$, R. S. S. Amorim ${ }^{3}$, L. Sanches ${ }^{4}$, J. H. Campelo Jr. ${ }^{3}$, and M. Weiler ${ }^{1}$ \\ ${ }^{1}$ Chair of Hydrology, Faculty of Environment and Natural Resources, University of Freiburg, Fahnenbergplatz, \\ 79098 Freiburg, Germany \\ ${ }^{2}$ Institute for Resources, Environment and Sustainability and Department of Earth, Ocean and Atmospheric Sciences, \\ University of British Columbia, 418-2202 Main Mall Vancouver, BC, V6T 1Z4 Canada \\ ${ }^{3}$ Departamento de Solos e Engenharia Rural, Faculdade de Agronomia e Medicina Veterinária e Zootecnica, Universidade de \\ Mato Grosso (FAMEVZ/UFMT), Avenida Fernando Correa da Costa no 2367 Boa Esperança, 78060900 Cuiabá, Brazil \\ ${ }^{4}$ Departamento de Engenharia Sanitária e Ambiental, Faculdade de Arquitetura, Engenharia e Tecnologia, Universidade de \\ Mato Grosso (UFMT), Cuiabá, Mato Grosso, Brazil, Avenida Fernando Correa da Costa no 2367, Boa Esperança, \\ 78060900 Cuiabá, Brazil
}

Correspondence to: J. Schwerdtfeger (julia.schwerdtfeger@ hydrology.uni-freiburg.de)

Received: 15 March 2014 - Published in Hydrol. Earth Syst. Sci. Discuss.: 10 April 2014

Revised: 11 August 2014 - Accepted: 2 October 2014 - Published: 5 November 2014

\begin{abstract}
Characterizing hydrological processes within tropical wetlands is challenging due to their remoteness, complexity and heterogeneity. In particular, estimates of evaporative water loss are inherently uncertain. In view of the large influence on the local and regional climate, the quantification of evaporation is essential for the determination of the water balance of permanent and intermittent water bodies. Data for tropical wetlands are scarce where their remoteness impedes direct evaporation measurements. Seasonal inundation dynamics affect evaporation processes in tropical wetlands, which can be analysed in two stages: the first stage during the wet season and the second stage during the dry season. As yet no adequate method exists for determining second-stage evaporation in a data-scarce environment that additionally allows for a transfer of simulated actual evaporation (AET) to other locations. Our study aimed at developing a process-based model to simulate first- and second-stage evaporation in tropical wetlands. We selected a set of empirical potential evaporation (PET) models of varying complexity, each based on different assumptions and available data sets, and evaluated the models with pan evaporation observations in the Pantanal of South America, one of the largest tropical wetlands in the world. We used high-resolution measurements of surface and groundwater levels at different locations to determine the water available for evaporation. AET
\end{abstract}

was derived by constraining simulated PET based on available water. The model of best fit was applied to different types of water bodies with varying hydroperiods to capture first- and second-stage evaporation across a range of wetland types. With our new model we could quantify evaporative water loss in the dry and the wet season for different locations in the Pantanal. This new spatially explicit approach represents an improvement in our understanding of the role of evaporation in the water balance of the Pantanal. We recommend the application of this model in other remote tropical wetlands, since only a minimum of input data is necessary.

\section{Introduction}

Evaporation is considered to be the dominant cause of water loss from most wetlands, particularly for tropical wetlands. The rate of evaporation can lower the water depth, which in turn affects inundation dynamics, inundation duration and wetland area (Burba et al., 1999). Evaporative water loss has major impacts on stream flow and on water storage (Melesse et al., 2009), which enables wetlands to buffer hydrological changes throughout the year (Wantzen et al., 2008). This flood control mechanism allows a high biodiversity to be supported, and is one of the most important ecosystem services 
provided by wetlands (Zedler and Kercher, 2005). Therefore, in order to manage wetland water resources, the quantification of evaporative water loss is crucial for a better understanding of the hydrological cycle (Drexler et al., 2004). For clarification, in this study the term evaporation refers to the overall water loss from a water surface or a land surface to the atmosphere.

Tropical wetlands constitute a special type of wetland characterized by a pronounced dry and wet season, which determines their inundation dynamics (Girard, 2011) and, in turn, affects the evaporation process. The determination of evaporative water loss in tropical wetlands is especially challenging since they are mostly characterized by remoteness, where lack of data is typical (Sanches et al., 2011). Changing water depth and the heterogeneity of wetland vegetation (Mohamed et al., 2012) complicate measurements in these environments (Silva and Girard, 2004). The estimation of evaporation requires highly accurate measurements (Drexler et al., 2004), which are rarely available in remote areas. Therefore, in such ecosystems, the challenge is to find the best trade-off between (i) a realistic representation of the system by capturing the dominant controls on the basis of limited data and (ii) an accurate description of the evaporation process (Shuttleworth, 1993). In this context, it is necessary to simplify common methods for estimating evaporation (Melesse et al., 2009). Due to a variety of approaches for estimating evaporative water loss in diverse wetland types, most reviews of wetland evaporation focus on a particular region (Drexler et al., 2004).

In tropical wetlands, the evaporation process during the year can be classified into two stages: in the first stage, where surface water is abundant and evaporation is only limited by available energy, potential evaporation (PET) rates are achieved; in the second stage, where a reduction in PET to actual evaporation (AET) takes place, evaporation is limited by soil water availability. The reduction factor is usually assumed to be a function of soil water content (Idso et al., 1974; De Bruin, 1983; Brutsaert and Chen, 1995; Jacobs et al., 2002; Brutsaert, 2005). The determination of second-stage evaporation in remote tropical wetlands is more complicated (De Bruin, 1983). Usually, wetland evaporation in the tropics is determined by PET models, such as Penman, Penman-Monteith or Priestley-Taylor (e.g. De Bruin, 1983; Sanches et al., 2010; Abtew and Melesse, 2013a), and compared to observed values from the Bowen ratio or eddy flux measurements (Jacobs et al., 2002; Abtew, 2004; Wang and Dickinson, 2012). Only few studies have focused on determining first- and second-stage evaporation separately. De Bruin (1983) used a simplified Priestley-Taylor equation to determine first-stage evaporation and verified the potential evaporation rate at 60 meteorological stations in the tropics. Second-stage evaporation was more variable, and AET depended mostly on the duration of the dry season. Jacobs et al. (2002) also reduced simulated PET on the basis of soil moisture information to determine second-stage evaporation, suggesting that a two-stage model is valid for sites with variable water table and soil water content. Shoemaker and Sumner (2006) corrected PET to AET using sitespecific correction factors based on the results of a study by German (2000) using a large data set from the Everglades. Yet, a model for determining first- and second-stage evaporation that allows for the transfer of evaporation results to other locations where no extensive data requirements are necessary does not exist for remote tropical wetland systems. Furthermore, groundwater may play an important role in these systems and capillary rise or access of plants to the saturated zone may alter second-stage evaporation, which is based on water availability.

Therefore, the aim of our study was to develop a processbased model which is capable of continuously simulating first- and second-stage evaporation capturing inundation dynamics as the dominant controls. Processes considered by the model include the impact of inundation dynamics as well as water table changes on evaporation losses from the wetland, which are both important processes of the wetlands water balance. Based on limited data, which is typical in tropical wetlands, we present a new and simplified approach to quantify evaporative water loss on a spatial scale for dry and wet years using only water level measurements. We evaluated our model in the Pantanal of South America, one of the largest tropical wetlands in the world, where up to $60 \%$ of water flowing into the wetland from tributaries is lost by evaporation (Gonçalves et al., 2011).

\section{Study site}

Our study took place in the northern Pantanal wetland of South America, a protected area known as the RPPN SESC Pantanal, managed by the Brazilian SESC (Serviço Social do Comércio, Commercial Social Service, Fig. 1a). The Pantanal is one of the largest freshwater wetlands worldwide and a very important ecosystem, with an area of around $150000 \mathrm{~km}^{2}$ (Gonçalves et al., 2011). The Ramsar Convention on Wetlands declared the RPPN SESC Pantanal as a Ramsar Site of International Importance (Ramsar Convention on Wetlands, 2011). We call the RPPN SESC Pantanal as study area in the following.

The Pantanal consists of alluvial fans of its main rivers, innumerable wetland lakes and a stream network crossing the whole floodplain (Por, 1995). The wetland lies in the tropical humid climate zone with distinct dry and wet seasons (Kottek et al., 2006). The average annual precipitation is around $1500 \mathrm{~mm}$, mostly taking place in the rainy summer months (November to April) (Ramsar Convention on Wetlands, 2011). The heavy rainfall causes inundations across the low-relief floodplain beginning usually in November or December in the northern part of the wetland. During the dry months of the Austral winter (May to October), the water level of the floodplain drops continuously. Small rivers 

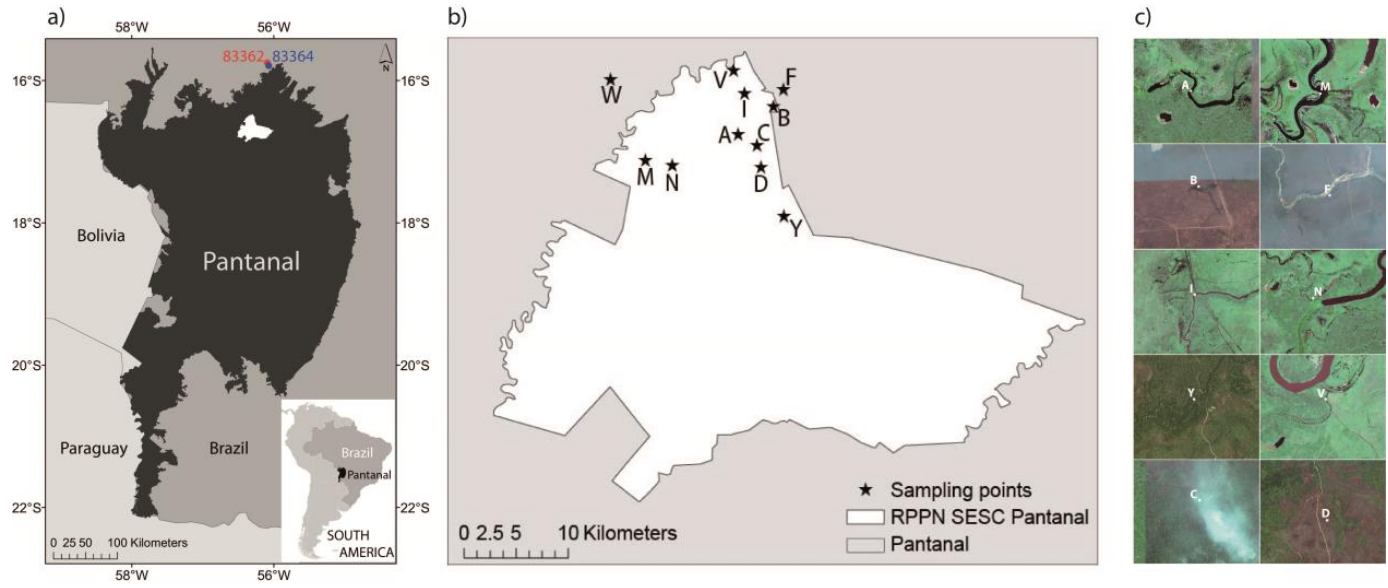

Figure 1. (a) Location of study area (RPPN SESC Pantanal, white background) in northern part of Brazilian Pantanal wetland of South America with Cuiabá Airport station (83362) and class A pan location (Padre Ricardo Remetter Station 83364); (b) location of sampling points; (c) studied water bodies (source: Google Earth).

and water bodies dry out completely (Girard, 2011), but some water bodies retain water throughout the dry season (Heckman, 1998). The mean monthly relative humidity in the rainy season is around $85 \%$ and can drop below $60 \%$ when the floodplain is dry. More than $70 \%$ of annual rainfall evaporates during the year (Girard, 2002). Evaporation estimations in the literature range between 1100 and $1600 \mathrm{~mm}$ (Ponce, 1995; Hasenack et al., 2003; Alho, 2008; Gonçalves et al., 2011; Girard, 2011). Eight months of the year there is a hydrological deficit, where PET is larger than precipitation. Precipitation in the dry winter is $<40 \mathrm{~mm}$ per month, caused by a stable climate with dry equatorial air masses brought by the Intertropical Convergence Zone (ITCZ) (Hasenack et al., 2003). Throughout the year air temperature remains high with a mean annual value of $25.7^{\circ} \mathrm{C}$ (Ramsar Convention on Wetlands, 2011). In the dry season afternoon temperatures can exceed $40^{\circ} \mathrm{C}$ (Heckman, 1998).

\section{Methodology}

To obtain simulated evaporation rates for different types of water bodies in the study area, we first calculated the available energy necessary to calculate PET. Second, we chose seven PET models based on the data available, and used class A pan recordings and five different measures of fit to evaluate their performance. Finally, by constraining simulated PET results using surface- and groundwater levels to determine water availability for evaporation, we derived AET for the range of water bodies within the study site and compared the simulated AET with observations from a Bowen ratio climate station. These different steps are outlined in detail below.

\subsection{Choice and performance of PET models}

Since radiation is the main factor that determines evaporation in the tropics (De Bruin, 1983), we chose seven PET models from radiation-based and more complex methods differing in the data requirements. Based on a detailed literature review, the parameter values for the models were taken from prior successful applications in the tropics (Table 1). The calculation of the input parameters on a daily basis and the equations used in the PET models selected are provided in Appendices $\mathrm{A}$ and $\mathrm{B}$.

Following 38 months of observations we calculated the agreement of PET model results and class A pan recordings using five different measures of fit (Table 2). For a rigorous model evaluation, Krause et al. (2005) recommend using a set of different measures of fit to consider the overall model performance including its variability, bias and peaks. To evaluate the models, we chose the best PET model for our study area by ranking the PET models according to each measure of fit and then to the average ranking to determine the best overall fit.

\subsection{Calculation of AET}

We used the groundwater evaporation function developed by Stoll and Weiler (2010), in which AET was derived by constraining simulated PET restricted by available water. This approach predicts AET based on the following relationship between evaporation rates and groundwater depth:

$\operatorname{AET}(t) \begin{cases}\operatorname{PET}(t) & \text { if } h(t) \geq d_{1} \\ \operatorname{PET}(t) \cdot\left(\frac{d_{2}-h(t)}{d_{2}-d_{1}}\right) & \text { if } h(t) \leq d_{1} \text { and } \geq d_{2} \\ 0 & \text { if } h(t) \leq d_{2},\end{cases}$

where $h(t)$ is the measured depth to water level, $d_{1}(\mathrm{~mm})$ is the depth down to which no reduction in PET takes place and 
Table 1. Input variables of all potential evaporation (PET) models utilized in this study and references where used and evaluated previously in the tropics (TUR = Modified Turc equation, ABT $=$ Simple Abtew equation, MAK = Modified Makkink equation, HAR = Hargreaves equation, $\mathrm{PEN}=$ Penman open water evaporation, $\mathrm{PMO}=$ Penman-Monteith combination equation, PRT $=$ Priestley-Taylor equation).

\begin{tabular}{lll}
\hline PET model & Input variable & References of use and evaluation in the tropics \\
\hline TUR & $T_{\max }, S_{\mathrm{t}}$ & Abtew (1996), Abtew and Melesse (2013b) \\
ABT & $S_{\mathrm{t}}, \lambda$ & Abtew (1996), Delclaux et al. (2007), Melesse et al. (2009), \\
& & Abtew et al. (2011) \\
MAK & $S_{\mathrm{t}}, \gamma, \lambda$ & Abtew and Melesse (2013b) \\
HAR & $T_{\mathrm{a}}, R_{\mathrm{S}}$ & Watanabe et al. (2004), Bautista et al. (2009), Saghravani et al. (2009) \\
PEN & $\gamma, \lambda, v, \Delta, R_{\mathrm{n}}$ & De Bruin (1983), Abtew (1996), Vardavas et al. (1996), Jacobs et al. (2002) \\
PMO & $\gamma, \lambda, \Delta, R_{\mathrm{n}}$, & De Bruin (1983), Abtew and Obeysekera (1995), Abtew (1996), Jacobs et al. \\
& $G, e_{\mathrm{S}}, e, \rho_{\mathrm{a}}$, & (2002),Mao et al. (2002), McJannet et al. (2008), Mohamed et al. (2012) \\
& $c_{\mathrm{p}}, r_{\mathrm{s}}, r_{\mathrm{a}}$ & \\
PRT & $\alpha_{\mathrm{PRT}}, \gamma, \lambda$, & De Bruin (1983), Abtew and Obeysekera (1995), Abtew (1996), Vardavas et \\
& $\Delta, R_{\mathrm{n}}$ & al. (1996), German (2000),Jacobs et al. (2002), Mao et al. (2002), Vourlitis et \\
& & al. (2002), Sanches et al. (2011) \\
\hline
\end{tabular}

Table 2. Measures of fit with their abbreviations and equations ( $N$ : number of time steps, $S$ : simulated, $O$ : observed, $\sigma(x)$ : standard deviation of $x, \mu(x)$ : mean of $x)$.

\begin{tabular}{lrl}
\hline Measure of fit & Abbreviation & Equation \\
\hline Root mean square error & RMSE & RMSE $=\sqrt{\frac{\sum_{N}(S-O)^{2}}{N}}$ \\
\hline Nash-Sutcliffe efficiency & NSE & NSE $=1-\frac{\sum_{N}(S-O)^{2}}{\sum_{N}(\bar{O}-O)^{2}}$ \\
\hline Kling-Gupta efficiency & & \\
\hline Spearman's rank correlation coefficient & KGE & KGE $=1-\sqrt{\left(r_{\mathrm{P}}-1\right)^{2}+\left(\frac{\sigma(S)}{\sigma(O)}-1\right)^{2}+\left(\frac{\mu(S)}{\mu(O)}-1\right)^{2}}$ \\
\hline Pearson's correlation coefficient & PCC & SRCC $=r_{\mathrm{SR}}$ \\
\hline
\end{tabular}

$d_{2}(\mathrm{~mm})$ is the extinction depth (Fig. 2). We calibrated the parameters $d_{1}$ and $d_{2}$ for the whole calibration period including first- and second-stage evaporation using a parameter sampling grid $(100 \times 100$ grid cells $)$ within predefined ranges in depths between 0 and $1500 \mathrm{~mm}$ for $d_{1}$ and between 2000 and $5000 \mathrm{~mm}$ for $d_{2}$. Here, we used only the mean absolute error (MAE) as a measure of fit to evaluate model performance of absolute amount of evaporation rates. Using absolute error measures such as MAE often provides more information about the model efficiency than other measures of fit (Legates and McCabe, 1999). The results of the groundwater evaporation function from Stoll and Weiler (2010) were evaluated by local measurements of AET with the Bowen ratio method at water body C (Fig. 1b) obtained from Sanches et al. (2011). The Bowen ratio method is a frequently used method to estimate evaporation based on the energy balance components, where sensible heat is related to latent heat (Tanner, 1960; Brutsaert, 2005).

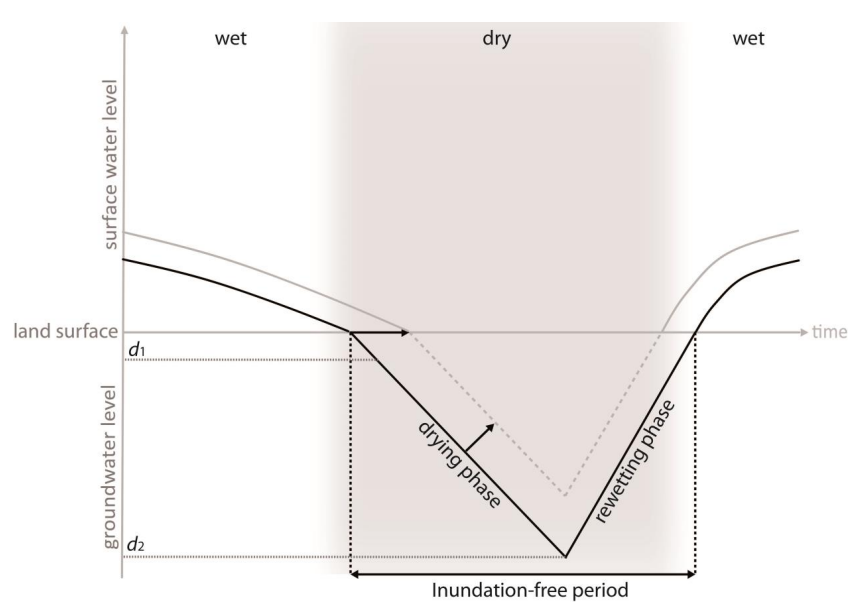

Figure 2. Schematic outline indicating the conceptual model of the drying and rewetting phases of water body $\mathrm{D}$ and its application to other locations with a different inundation dynamic (grey line). 
Table 3. Data availability ( $+=$ available,$-=$ not available or reference to data source).

\begin{tabular}{|c|c|c|c|}
\hline Parameter & $\begin{array}{l}\text { Ranking period: } \\
\text { Data used to evaluate PET } \\
\text { model performance } \\
\text { (February 2010-April 2013) }\end{array}$ & $\begin{array}{l}\text { Calibration period: } \\
\text { Data used to calibrate and } \\
\text { evaluate the reduction of PET to } \\
\text { AET ( } 26 \text { January-10 December 2007) }\end{array}$ & $\begin{array}{l}\text { Study period: } \\
\text { Data used to apply ourmodel } \\
\text { to different locations } \\
\text { (28 April 2012-27 April 2013) }\end{array}$ \\
\hline$T_{\mathrm{a}}, \mathrm{RH}, v, P_{\mathrm{a}}, T_{\mathrm{W}}$ & + & + & + \\
\hline Cloud cover & from OGIMET & from OGIMET & from OGIMET \\
\hline Class A pan & + & + & + \\
\hline Bowen ratio & - & from Sanches et al. (2011) for water body C & - \\
\hline$K_{\mathrm{p}}$ & after Orang (1998) $R^{2}=0.39$ & after Orang (1998), $\quad R^{2}=0.34$ & after Cuenca (1989), $R^{2}$ of 0.49 \\
\hline Water level & - & + & + \\
\hline
\end{tabular}

\subsection{Application to different locations}

We selected the best-performing PET model to apply our new model to different locations in the study area. The calibration results of $d_{1}$ and $d_{2}$ from water body $\mathrm{C}$ defined the water availability for different locations in the study area. To define water available for evaporation in the dry and the wet season, we used high-resolution measurements of surface and groundwater levels. Water level measurements were obtained by ten Odyssey capacitance probes (Dataflow Systems Ltd, New Zealand) installed in the study area at different locations with different inundation dynamics (Fig. $1 \mathrm{~b}$ and c). Only two of these capacitance probes (C and D) measured both surface and groundwater levels. They were installed in the soil $(5 \mathrm{~m}$ length in total reaching from $3 \mathrm{~m}$ below the soil surface to $2 \mathrm{~m}$ above) to measure groundwater levels during the dry season and surface water levels during inundation. All other probes were installed at the ground surface, and thus measured only surface water levels. We used the probe installed in the study area with the longest inundation-free period (probe D) to estimate groundwater levels for all other locations.

We determined the drying phase of water body $\mathrm{D}$ to start from the first decrease in groundwater levels from the ground surface to the lowest measured groundwater level in the dry season. From there, the rewetting phase was considered as the period of rising groundwater levels up to the day where the water level again reached the ground surface (Fig. 2). We did not consider smaller groundwater level fluctuations during the drying and rewetting phases. Linear regressions were calculated for both phases of observed groundwater levels, where data were available. These regression-derived groundwater levels of water body D were transferred to all other locations by shifting the drying and rewetting phases with their specific slopes based on the duration of their inundation-free periods in the dry season. This approach assumes that the rate of decreasing and increasing groundwater levels in the dry season is consistent in time and space. We evaluated this assumption by applying the predicted groundwater levels from water body $\mathrm{D}$ against observed groundwater levels from water body $\mathrm{C}$.

\subsection{Data and measurements}

Table 3 lists the available data for our study. The measurements of air temperature $\left(T_{\mathrm{a}}\left[{ }^{\circ} \mathrm{C}\right]\right)$, relative humidity ( $\mathrm{RH}$ $[\%])$, wind velocity $\left(v\left[\mathrm{~m} \mathrm{~s}^{-1}\right]\right)$ and barometric pressure $\left(P_{\mathrm{a}}\right.$ $[\mathrm{hPa}])$ took place at three different meteorological stations (C, D and W in Fig. 1b). All measuring devices were connected to data loggers (Campbell Scientific model CR-1000, Campbell Scientific International, Logan Utah). Measurements at $30 \mathrm{~s}$ intervals were averaged every $30 \mathrm{~min}$ and these 48 daily recordings were used to derive mean daily values for $T_{\mathrm{a}}$, maximum $\left(T_{\max }\right)$ and minimum air temperature $\left(T_{\min }\right)$, mean daily RH, $v$ and $P_{\mathrm{a}}$. We measured water levels continuously every $30 \mathrm{~min}$, after which the 48 daily recordings were averaged to mean daily water level values. Water temperature $\left(T_{\mathrm{w}}\left[{ }^{\circ} \mathrm{C}\right]\right)$ of all water bodies was measured in situ during water sampling campaigns every 3-4 weeks. $T_{\mathrm{w}}$ was also measured continuously at water body $\mathrm{C}$ every 30 min with a TruTrack WT-HR water height data logger. For periods of water absence in the dry season, we correlated $T_{\mathrm{w}}$ with daily $T_{\mathrm{a}}\left(R^{2}=0.6\right)$ and corrected the bias with our in situ $T_{\mathrm{w}}$ measurements. Since daily cloud cover data were not available for the study area, they were obtained from the weather information service provided by OGIMET (www.ogimet.com) for the meteorological station closest to the study area (Cuiabá Airport station 83362, Aeroporto Internacional de Cuiabá - Marechal Rondon). We used these data to calculate daily mean solar radiation according to the standard approach from Shuttleworth (1993) (details in Appendix A). The mean height of all sampling points in the study area was $122 \mathrm{~m}$ a.s.l.

Class A pan recordings were taken from the data obtained by the National Institute of Meteorology (Instituto Nacional de Meteorologia, INMET) for the closest meteorological station (Padre Ricardo Remetter Station 83364). We multiplied them by a site-specific pan coefficient $K_{\mathrm{p}}$ to reduce pan evaporation, which is higher compared to open water evaporation. The $K_{\mathrm{p}}$ value, which was not found in the Pantanal literature, was determined using a standard procedure, where class A pan recordings multiplied by $K_{\mathrm{p}}$ values were compared to PET rates calculated with the FAO 


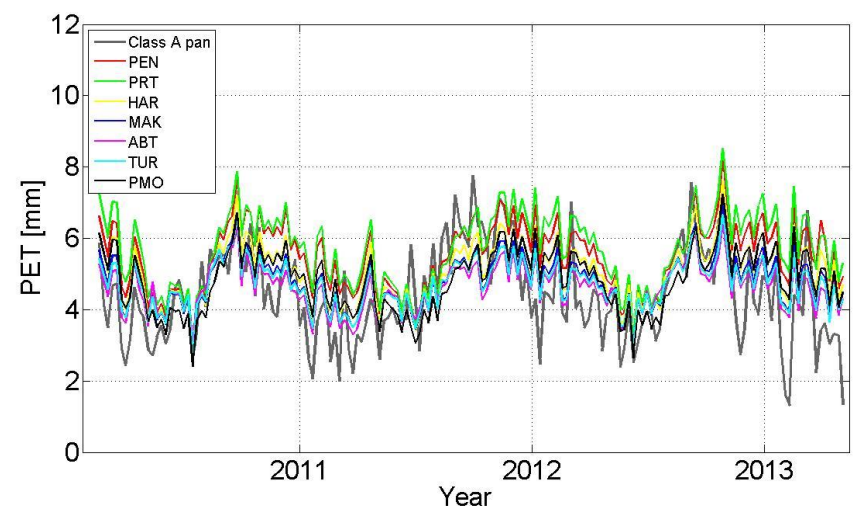

Figure 3. Comparison of PET models with class A pan recordings on a weekly mean basis (February 2010-April 2013).

Penman-Monteith equation (Allen et al., 1998). Approaches used for the $K_{\mathrm{p}}$ calculation are given in Table 3 . To verify the representativeness of class A pan recordings for our study area, we compared the most important meteorological variables from both locations.

\section{Results}

\subsection{Performance of PET models}

In a comparison of the meteorological variables recorded at the class A pan location with the meteorological measurements from our study area, at all three meteorological stations the coefficient of determination $\left(R^{2}\right)$ for mean monthly values of $T_{\mathrm{a}}, \mathrm{RH}$ and $v$ was greater than $0.55,0.84$ and 0.38 respectively. These coefficients justified the use of the class A pan recordings for testing the selected PET models. Our calculated $K_{\mathrm{p}}$ values ranged between 0.82 and 0.93 for the ranking period, between 0.72 and 0.88 for the calibration period and between 0.79 and 0.93 for the study period (Table 3). Mean net radiation $\left(R_{\mathrm{n}}\right)$ for the calibration period was $16.3 \mathrm{MJ} \mathrm{m}^{-2}$ day $^{-1}$. Net radiation was highest at the end of the dry season, with a maximum monthly mean of $20.0 \mathrm{MJ} \mathrm{m}^{-2}$ day $^{-1}$ in October. $R_{\mathrm{n}}$ values were lowest at the beginning of the dry season, with a minimum value of $12.9 \mathrm{MJ} \mathrm{m}^{-2} \mathrm{day}^{-1}$ in June. Maximum cloud cover occurred in the wet season months of January and February with a mean monthly maximum of 56 and $55 \%$, respectively. Minimum cloud cover was found in the dry season, with a mean monthly of $5 \%$ in August. Appendix C provides the measurements for the input parameters.

Comparing the data recorded with the class A pan over 38 months to the results from the PET models, we found that the models adequately represented the overall PET dynamics observed by the class A pan (Fig. 3). Simulated PET values were higher in the dry winter months and lower in the wet summer months. Daily variations in class A pan recordings
Table 4. Minimum (min), maximum (max), mean values (mean) and standard deviations (std) of PET model results for the study period (28 April 2012-27 April 2013).

\begin{tabular}{lrrrrrrr}
\hline & TUR & ABT & MAK & HAR & PEN & PMO & PRT \\
\hline $\min$ & 1.9 & 1.8 & 1.6 & 1.6 & 2.0 & 1.6 & 1.9 \\
$\max$ & 7.6 & 7.2 & 7.6 & 8.4 & 14.2 & 8.2 & 9.6 \\
mean & 5.0 & 4.7 & 4.9 & 5.2 & 5.9 & 5.0 & 5.9 \\
std & 1.1 & 1.0 & 1.1 & 1.3 & 1.7 & 1.2 & 1.4 \\
\hline
\end{tabular}

Table 5. Results of PET performance based on a ranking of the PET models according to the best overall fit for all five measures of fit.

\begin{tabular}{lrrrrrrr}
\hline & TUR & ABT & MAK & HAR & PEN & PMO & PRT \\
\hline RMSE & 0.99 & 0.99 & 1.02 & 1.16 & 1.47 & 1.16 & 1.69 \\
NSE & 0.44 & 0.45 & 0.40 & 0.24 & -0.23 & 0.23 & -0.63 \\
KGE & 0.45 & 0.42 & 0.46 & 0.50 & 0.49 & 0.45 & 0.44 \\
SRCC & 0.75 & 0.73 & 0.71 & 0.68 & 0.65 & 0.59 & 0.59 \\
PCC & 0.73 & 0.72 & 0.70 & 0.68 & 0.65 & 0.58 & 0.58 \\
Mean rank & 2.2 & 2.6 & 3 & 3.4 & 4.8 & 5.2 & 6.8 \\
Final rank & 1 & 2 & 3 & 4 & 5 & 6 & 7 \\
\hline
\end{tabular}

were more dynamic than in the PET models. Table 4 gives the minimum, maximum and mean values, and the standard deviations simulated in all PET models for the study period. The Turc model (TUR), modified for subtropical regions proved to be the PET model of best overall fit in our study area (Table 5). The RMSE of TUR was 0.99 , which corresponded to $18 \%$ of the mean simulated value. The results of NSE, KGE, SRCC and PCC ranged between 0.44 and 0.75 .

\subsection{Calculation of AET}

In order to calculate AET by applying the groundwater evaporation function after Stoll and Weiler (2010), we used the drying and rewetting phases of water body $\mathrm{D}$ to derive a regression of decreasing and increasing groundwater levels (Fig. 5). The coefficients of determination $\left(R^{2}\right)$ were calculated to 0.99 and 0.97 and the slopes to -18 and $+39 \mathrm{~mm} \mathrm{day}^{-1}$ for the drying and rewetting phases, respectively. To evaluate our approach, we compared measured groundwater levels of the second groundwater probe installed in water body $\mathrm{C}$ with predicted groundwater levels from the probe installed in water body $\mathrm{D}$ for the days where measured groundwater level data of probe $\mathrm{C}$ were available (10 June-22 July 2012) and obtained a $R^{2}$ of 0.98 . For elaboration of the procedure the results of transferring the drying and rewetting phase of water body $\mathrm{D}$ to the inundation-free period of water body B are shown in Fig. 6 .

The parameters $d_{1}$ and $d_{2}$ were calibrated to 0 and $2990 \mathrm{~mm}$, respectively, with a MAE of $0.54 \mathrm{~mm}$ for the simulated evaporation rate. In the end of the wet season (January-April 2007), simulated AET was equivalent to simulated PET determined by the TUR model (Fig. 4a). As soon 


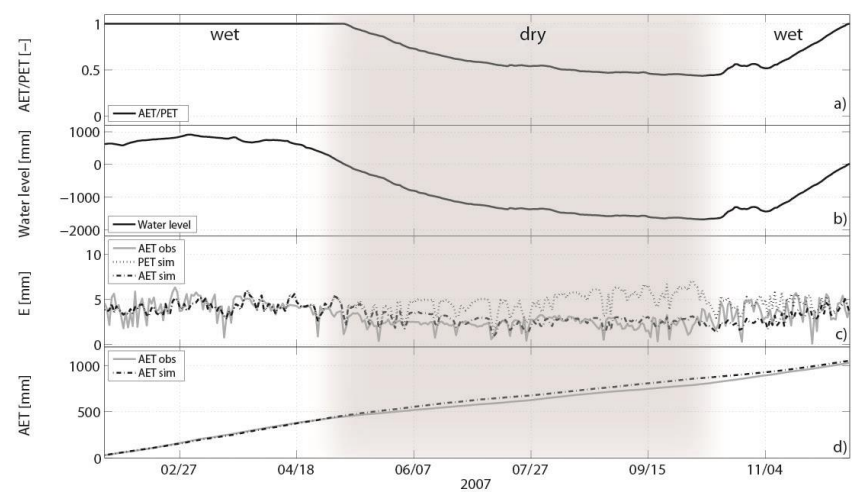

Figure 4. (a) Relative simulated AET to simulated PET at water body $\mathrm{C}$ for the dry and the wet season of the calibration period (26 January-10 December 2007); (b) water level at water body C; (c) comparison of simulated AET with simulated PET and observed AET; (d) cumulative sums of observed and simulated AET.

as the surface water was depleted in the drying phase (end of inundation) the relation of AET to PET started to decrease (May to September). At the end of the dry season (October), simulated AET was only $44 \%$ of PET. Their ratio became $100 \%$ again as the groundwater level reached the ground surface in the rewetting phase of the next wet season (Fig. 4b). Simulated AET adequately represented observed AET in terms of daily dynamic and cumulated AET. Comparing our simulated monthly means of evaporation rates to published values by Sanches et al. (2011), the maximum difference was $0.8 \mathrm{~mm} \mathrm{day}^{-1}$ and the coefficient of determination $\left(R^{2}\right)$ was 0.76. Evaporation rates in the dry season clearly decreased in relation to simulated PET (Fig. 4c). Evaporation rates of simulated PET ranged between 1.6 and $7.0 \mathrm{~mm}$, with a mean value of $4.5 \mathrm{~mm}$ and a standard deviation of $1.0 \mathrm{~mm}$. Evaporation rates of observed and simulated AET ranged between 0 and $6.3 \mathrm{~mm}$ as well as 0.9 and $6.0 \mathrm{~mm}$, with mean values of 3.1 and $3.3 \mathrm{~mm}$ and standard deviations of 1.4 and $1.0 \mathrm{~mm}$, respectively. Simulated PET rates were highest at the end of the dry season and observed and simulated AET values were highest in the wet season. Mean weekly simulated AET corresponded well with observed AET for the calibration period over the whole study period (Fig. 4d). The total sum of observed and simulated AET for the calibration period was 1042 and $1062 \mathrm{~mm}$, respectively, differing only by $2 \%$. At the end of the wet season, simulated AET slightly underestimated observed AET, while in the dry season the simulated AET slightly overestimated observed AET.

\subsection{Application to different locations within the study area}

AET and PET were simulated for all water bodies throughout the study period (Fig. 7). The permanent water body A showed a ratio of simulated AET to simulated PET of 1 throughout the whole study period. Smallest AET to PET ratios were found in the seasonally inundated floodplain $(\mathrm{C}$ and D), where simulated AET dropped to 0 during the study period. The reduction in ratios of simulated AET to simulated PET for all other water bodies ranged between 32 and $68 \%$. The minimum of estimated groundwater levels was found between 19 September and 6 November 2012.

Figure 8 shows the strong covariance between total AET $[\mathrm{mm}]$ and hydroperiod (annual duration of inundation [days]) for the different types of studied water bodies (permanent, ephemeral, floodplain). Water bodies with highest total AET had the longest hydroperiod. The correlation of simulated AET and the hydroperiod was $R^{2}=0.93$. Water body A was the only permanent lake maintaining surface water during the whole study period, where the total AET for the study period was $1829 \mathrm{~mm}$. The floodplain itself (C and D) showed the shortest hydroperiod in the dry season with 128 and 63 days, respectively. All other bodies were ephemeral with differences in their hydroperiod ranging from 205 to 285 days.

\section{Discussion}

\subsection{Model performance}

Abtew (1996) and Abtew and Melesse (2013b) applied the modified Turc model to humid subtropical regions in the Everglades in South Florida where mean annual $T_{\max }$ and mean annual RH are $23.1{ }^{\circ} \mathrm{C}$ and $85 \%$, respectively (Abtew, 2004). They found a $70 \%$ correlation between open water evaporation measured with a lysimeter and simulated PET. Abtew and Melesse (2013b) assumed that, for humid subtropical regions, daily $T_{\max }$ correlates better with PET than mean $T_{\mathrm{a}}$. This was also the case in our study area in the Pantanal, which has similar climatological characteristics to the Everglades and is located in the same tropical humid climate zone with a dry and a rainy season (Kottek et al., 2006).

Our conceptual model of the drying and rewetting phases of the groundwater table introduced here is applicable in the calculation of the water available for evaporation in the Pantanal. Luo et al. (2009) state that a linear groundwater evaporation function is suitable for shallow groundwater tables and describe effectively the relationship between groundwater evaporation rates and groundwater depth. Shallow groundwater tables are typical in the Pantanal region (Girard, 2011). The calibrated extinction depth $d_{2}$ was $2.99 \mathrm{~m}$, which corresponds to the end of the deep root zone (Harbaugh, 2005). This is consistent with a study by Schenk and Jackson (2002), who found a similar medium root depth for tropical savannah. Canadell et al. (1996) assessed the rooting depths of different biomes and reported rooting depths between 1.8 and $19 \mathrm{~m}$ for tropical grassland and savannah in Brazil. In contrast to Souch et al.'s (1998) study, in which evaporation rates were not substantially reduced until the water dropped below the root zone, we find a reduction in evaporation rates beginning directly below the 


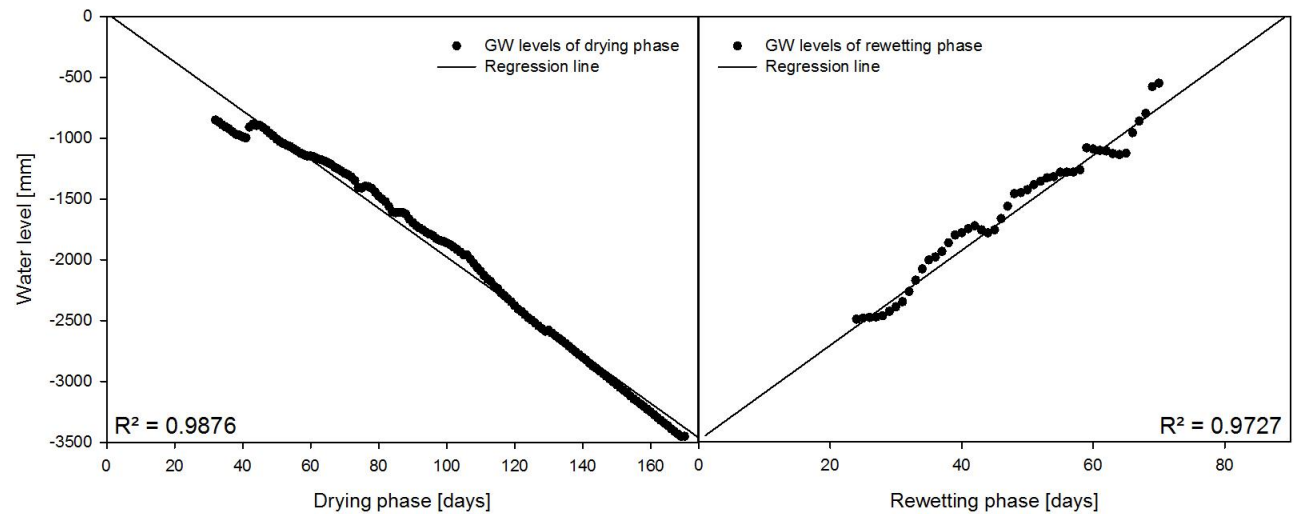

Figure 5. Measured and predicted groundwater levels of the drying and rewetting phases of location D (GW= groundwater).

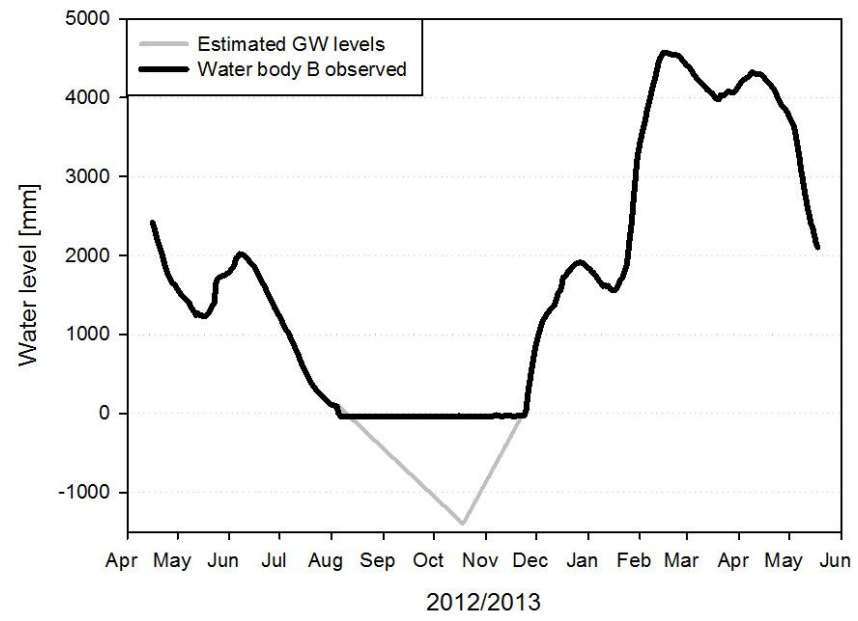

Figure 6. Drying and rewetting phases for the inundation-free period of water body $\mathrm{B}(\mathrm{GW}=$ groundwater $)$.

ground surface. This means that the reduction in PET values in our study began directly at the end of the inundation period. This difference might be due to low water retention capacities of sandy deposits in the alluvium in the Pantanal (Couto and De Oliveira, 2008; Johnson et al., 2013), which accelerates the drying process in the upper soil layer.

We evaluated our AET model results with local Bowen ratio measurements provided by Sanches et al. (2011). Our simulated mean annual evaporation rate of $3.3 \mathrm{~mm}$ was identical to their result. The small difference of only $2 \%$ between observed and simulated accumulated daily AET confirms that our model provides an adequate representation of both the first- and second-stage evaporation. While the underlying notion of describing the evaporation process in two stages is already widely accepted (Brutsaert and Chen, 1995), our study emphasizes the importance of considering first- and second-stage evaporation in the tropical wetlands in view of the differences in inundation times. The calculation of AET correlated highly $\left(R^{2}=0.93\right)$ with the hydroperiod.

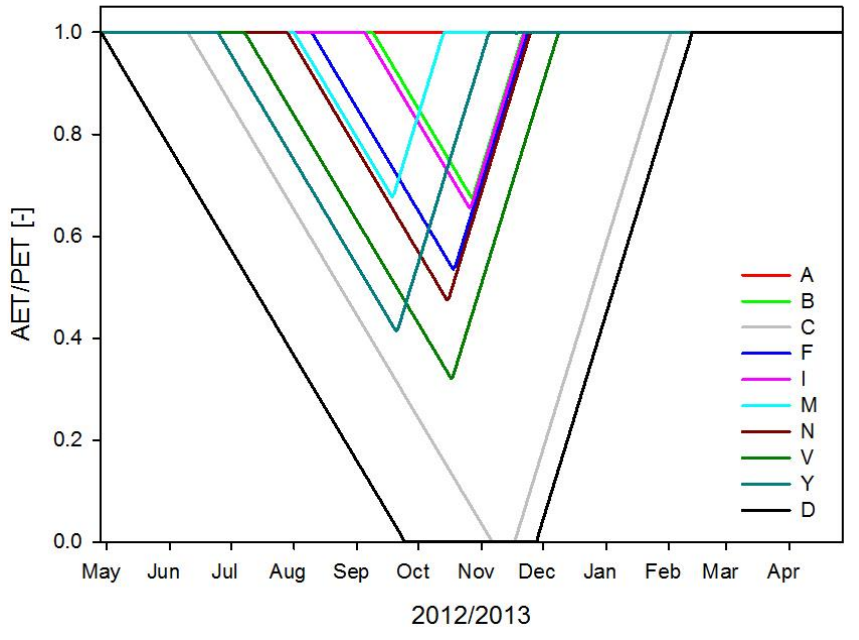

Figure 7. Predicted AET to PET ratios for all water bodies.

De Bruin (1983) also found that, in areas with a pronounced dry season, the duration of the dry period controls the deviation of AET from PET.

Quantifying evaporative water losses of different floodplain lakes improved our understanding of the role of evaporation in the water balance in the lakes studied. We can deduce from our study that AET of studied wetland lakes in the floodplain was different among the lakes, which corresponds with the findings of previous water balance studies in the same area (Schwerdtfeger et al., 2013). To study the reasons for the different inundation dynamics was beyond the scope of this study. One explanation may be the differences in the micro-topography together with soil types that either impede or accelerate infiltration, and therefore the drying process at a specific location (Bruland et al., 2006). Furthermore, local and regional groundwater fluxes, already observed in the study area (Schwerdtfeger et al., 2013), could also be the reason for discontinuous water level declines or mixing of water level signals induced by lateral connectivity between the water bodies (Tamea et al., 2010). 


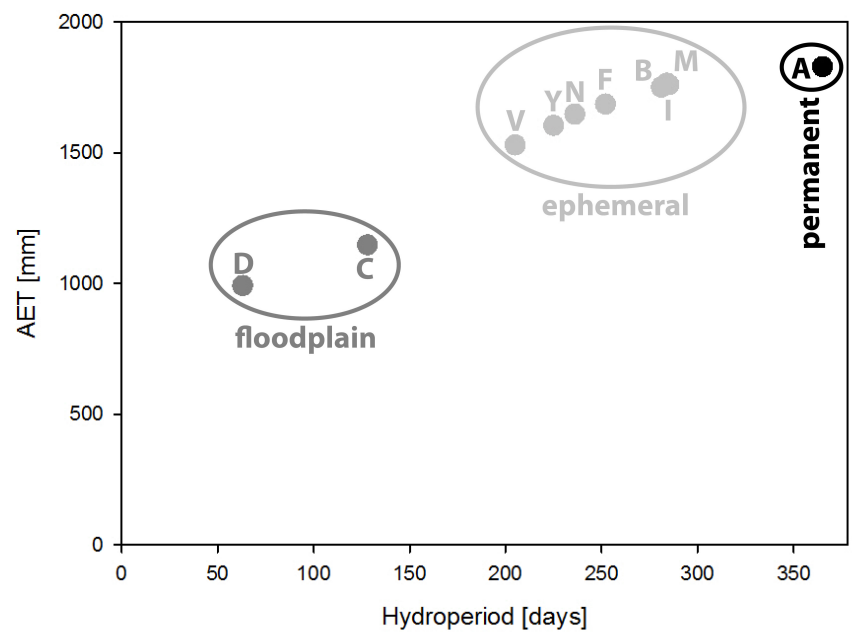

Figure 8. Relationship between total AET [mm] and hydroperiod (annual duration of inundation [days]) for studied water bodies (permanent, ephemeral, floodplain).

Our results confirm that even during the dry season the evaporation process is still very important (Mesquita et al., 2009). However, the reduction in PET due to the restriction in water available for evaporation needs to be considered while quantifying evaporative water losses on a spatial scale to assess the evaporation term in the wetlands water balance. Since large quantities of water inundating the wetland through inflow from tributaries and precipitation are lost through evaporation, it is essential that the evaporation term be quantified as accurately as possible. In the Pantanal literature studies hardly state if they refer to AET or PET (Ponce, 1995; Hasenack et al., 2003; Alho, 2008; Gonçalves et al., 2011; Girard, 2011) and rarely elucidated estimates of evaporation in the Pantanal lack the possibility to transfer evaporation estimates to different locations (Biudes et al., 2009; Sanches et al., 2010, 2011; Mesquita et al., 2009). Our simulated evaporation rates are therefore one of the first modelling approaches undertaken in the Pantanal, since the number of evaporation studies remains limited for the Pantanal. Our approach enabled us to quantify evaporative water losses on a temporal and spatial scale for the dry and the wet season.

\subsection{Reliability of proposed model}

\subsubsection{Data uncertainty}

Input data used in the calculation of the available energy for evaporation represent a source of uncertainty since measured solar radiation is not available at meteorological stations in or near the study area. The incoming radiation term depends more on astronomical rather than on local conditions of the climate (Shuttleworth, 1993). In the tropics the energy available at the ground surface, calculated on the basis of cloud cover, controls evaporation (Souch et al., 1998). To obtain the cloud cover data required we used these data from the Cuiabá Airport station (100 km north of study area), which were assumed to be similar to our study area since the climate in the region is determined by the movement of the ITCZ on a large scale (Hasenack et al., 2003). As our model adequately simulated PET, this assumption was justified. Due to the lack of local class A pan recordings for our study area, we used class A pan data from the nearest station $(80 \mathrm{~km}$ north of the study area) based on the assumption that the climate classification still is the same. For both locations, the climate classification after Kottek et al. (2006) is defined as Aw, which means equatorial savannah with dry winter and minimum precipitation $<60 \mathrm{~mm}$. This is reflected by the coefficients of determination between observed and simulated PET given in the results section. Our calculated $K_{\mathrm{p}}$ values to determine open water evaporation from class A pan recordings are in a realistic range compared to other studies (e.g. $K_{\mathrm{p}}=0.85$ in Doorenbos and Pruitt, 1977).

\subsubsection{Uncertainty due to simplified representation in the model}

Drexler et al. (2004) argue that empirical equations for estimating evaporation rates are highly simplified. Nevertheless, they also state that such easy and low-cost methods constitute perhaps the only practical method for data-scarce regions. Our new approach enabled us to quantify evaporative water loss in the dry and the wet season considering inundation and groundwater dynamics of a tropical wetland using only water level measurements and with the use of a PET model requiring only basic meteorological data.

In our study it was necessary to adopt a simplified approach to compensate for the lack of available relevant data. While PET is defined as the maximum possible rate of evapotranspiration from an area completely covered by actively growing vegetation (Brutsaert, 2005), we could not consider the transpiration process explicitly because no vegetation cover data were available, and reliable evapotranspiration estimates must be based on in situ vegetation cover measurements (Idso, 1981). Nevertheless, none of our water bodies had a permanent vegetation cover over the year since especially flowing carpets of water hyacinths, often seen in the study area, are very heterogeneous. The heterogeneity of vegetation is a typical characteristic in wetlands and the wetland literature shows no consensus about the ratio of wetland evaporation (with vegetation) to open water evaporation (McMahon et al., 2012) because it depends on biophysical characteristics of the wetland (Mohamed et al., 2012). Another source of uncertainty is neglecting the water table effects of specific yield, which is discussed in wetland research by Hill and Neary (2007), Sumner (2008), Tamea et al. (2010) or McLaughlin and Cohen (2014). 


\subsection{Transferability}

The potential uncertainty in the model due to the way in which we considered the drying and rewetting in our approach did not appear to influence our results significantly. The high correlation of predicted groundwater levels derived from the drying and rewetting phases at one groundwater probe (water body D) with observed groundwater levels at the other groundwater probe (water body C) meant we could apply our approach to different locations in the study area with confidence. We explain how our approach can be transferred to other locations in the study area with the very flat topography in the Pantanal. The plain is filled with sedimentary deposits (Irion et al., 2011), dominated by fine-grained sands, which result in a high permeability of the study area fostering a simultaneous receding of the water level in the study area. The duration between the end of the drying and the beginning of the rewetting phase corresponds well with the end of the dry season, which is usually in October (Heckman, 1998). Based on the reasonable results for our study area, which can be seen as representative for the Northern Pantanal wetland, we are convinced that our general approach is applicable in other remote tropical wetland systems. Of course, the best model, either Turc or another PET model depending on the data availability, must first be selected and validated for the specific region.

\section{Conclusions}

The aim of our study was to develop and evaluate a processbased model to simulate first- and second-stage evaporation in tropical wetlands that allow for the transfer of evaporation results to other locations using only water level measurements. The Turc model modified for humid subtropical regions best represented PET in our study area. Only data for solar radiation, which can be derived empirically, and daily maximum air temperature, generally available from every standard meteorological station, are required. The Turc model calculated first-stage evaporation at its potential rate under wet conditions, which was evaluated using local class A pan recordings. Second-stage evaporation during the dry season was addressed in a groundwater evaporation function that defined the quantity of water available for evaporation. Our new AET model was calibrated and evaluated with local Bowen ratio measurements. To apply our approach to different locations in the study area, one groundwater level probe in the study area seems sufficient to determine the general process of drying and wetting phases for inundation-free periods. We defined different types of water bodies based on their respective hydroperiod. Finally, surface and groundwater levels of these water bodies served to quantify evaporative water losses from different types of water bodies in the dry and wet season in the Pantanal, one of the largest tropical wetlands worldwide. Our conceptual model of the drying and rewetting phases of groundwater describes the relationship between groundwater evaporation rates and groundwater depth and can be used to determine the water available for evaporation in the Pantanal.

Our approach enables one to understand better hydrological processes in tropical wetlands and to shed light on the dominant process of water loss in such a pristine ecosystem with little prior hydrological information. We present a novel, simple yet effective approach to facilitate quantifying evaporative water loss on a spatial scale for dry and wet years with minimum of data input. The benefit of this model lies in the ability to simulate evaporative water loss in tropical wetland ecosystems using a minimum of basic climatic data readily available. Our new approach may also be used for large-scale applications or climate and land use change implications. 
Appendix A: Calculation of short- and long-wave radiation (Shuttleworth, 1993)

The relative distance between the Earth and the sun (dimensionless) $d_{\mathrm{r}}$ is given by the following equation:

$d_{\mathrm{r}}=1+0.033 \cos \left(\frac{2 \pi}{365} J\right)$,

where $J$ is the Julian Day Number. The solar declination $\delta$ in radians is calculated by

$\delta=0.4093 \sin \left(\frac{2 \pi}{365} J-1.405\right)$.

The sunset hour angle $\omega_{s}$ in radians is given by

$\omega_{\mathrm{s}}=\arccos (-\tan \Phi \tan \delta)$,

where $\Phi$ is the latitude of the study site (negative for the Southern Hemisphere). The sunset hour angle is used to calculate the maximum possible daylight hours $N(\mathrm{~h})$ :

$N=\frac{24}{\pi} \omega_{\mathrm{s}}$

Then, the extra-terrestrial solar radiation $S_{\mathrm{o}}$ in $\mathrm{MJ} \mathrm{m}^{-2} \mathrm{day}^{-1}$ is

$S_{\mathrm{o}}=\frac{G_{\mathrm{sc}} \cdot d_{\mathrm{r}}}{\pi}\left(\omega_{\mathrm{s}} \sin \Phi \sin \delta+\cos \Phi \cos \delta \sin \omega_{\mathrm{s}}\right)$,

where $G_{\mathrm{sc}}$ is the solar constant being $118.11 \mathrm{MJ} \mathrm{m}^{-2}$ day $^{-1}$. The saturated vapour pressure $e_{\mathrm{S}}$ in $\mathrm{kPa}$ can be calculated by

$e_{\mathrm{s}}=0.6108 \exp \left(\frac{17.27 T_{\mathrm{a}}}{237.3 T_{\mathrm{a}}}\right)$,

where $T_{\mathrm{a}}$ is the daily mean air temperature in ${ }^{\circ} \mathrm{C}$. For a physically based model of evaporation calculation the gradient of the function $\mathrm{d} e_{\mathrm{s}} / \mathrm{d} T$ in $\mathrm{KPa}^{\circ} \mathrm{C}^{-1}$ is calculated by

$\Delta=\frac{4098 e_{\mathrm{s}}}{\left(237.3+T_{\mathrm{a}}\right)^{2}}$.

For calculating the saturated vapour pressure deficit, it is necessary to calculate as well the saturated vapour pressure at $T_{\min }$ and $T_{\max }$. It was calculated the same way (Eq. A6) using $T_{\max }$ and $T_{\min }$, respectively, instead of $T_{\mathrm{a}}$. The vapour pressure $e$ in $\mathrm{kPa}$ at a given $\mathrm{RH}$ can then be derived from

$e=e_{\mathrm{S}} \cdot\left(\frac{\mathrm{RH}}{100}\right)$,

where RH is relative humidity in \%. Measured values of the vapour pressure deficit $D$ in $\mathrm{kPa}$ were not available at the study site. Therefore it has to be derived from micrometeorological measurements. With available data of $T_{\max }$ and $T_{\min }$ it can be calculated with the following equation:

$D=\left[\frac{e_{\mathrm{s}}\left(T_{\max }\right)+e_{\mathrm{s}}\left(T_{\min }\right)}{2}\right] \frac{1-\mathrm{RH}}{100}$.
The energy used for phase change from liquid to vapour during the process of ET is the latent heat of vaporization in $\mathrm{MJ} \mathrm{kg}^{-1}$. This energy required for separating the molecules can be derived from

$\lambda=2.501-0.002361 \cdot T_{\mathrm{s}}$

where $T_{\mathrm{S}}$ is the surface temperature of the water in ${ }^{\circ} \mathrm{C}$. The psychrometric constant $\gamma$ in $\mathrm{kPa}^{\circ} \mathrm{C}^{-1}$ is derived from

$\gamma=0.0016286 \cdot \frac{P}{\lambda}$,

where $P$ is the atmospheric pressure in $\mathrm{kPa}$, measured in the study area at three meteorological stations. The albedo for open water $\alpha_{\text {ow }}$ was set to 0.08 . In general the Angstrom coefficients $a$ and $b$ vary with a change in latitude, height of the station, albedo, mean solar altitude, vapour and pollution concentration in the air (Martínez-Lozano et al., 1984). Many approaches to derive the Angstrom coefficients have been undertaken. In this study $a$ and $b$ were derived from the approach after Glover and McCulloch (1958) due to restriction in data availability. This approach depends only on the latitude of the study site and can be formulated with

$a=0.29 \cos \Phi$,

which result in a value of $a=0.28$ in our case. The $b$ was set to 0.52 since it was practically constant. These correspond well with the values given in (Shuttleworth, 1993) $(a=0.25$ and $b=0.5$ ) for average climates, when there is not enough information available for calculating the Angstrom coefficients. The Angstrom coefficients are used to calculate $S_{\mathrm{t}}$, which is the solar radiation or total incoming short-wave radiation in $\mathrm{MJ} \mathrm{m}^{-2}$ day $^{-1}$ derived from

$S_{\mathrm{t}}=\left(a+b \frac{n}{N}\right) \cdot S_{\mathrm{o}}$

with $n N^{-1}$ as the cloudiness factor. The $n$ are the bright sunshine hours of a day and $N$ is the total day length already explained above. With the solar radiation $S_{\mathrm{t}}$ the net short-wave radiation $S_{\mathrm{n}}$ in $\mathrm{MJ} \mathrm{m}^{-2}$ day $^{-1}$ is calculated by

$S_{\mathrm{n}}=(1-\alpha) \cdot S_{\mathrm{t}}$

This is the part of short-wave radiation, where losses due to reflections are taken into account. The long-wave net radiation $L_{\mathrm{n}}$ in $\mathrm{MJ} \mathrm{m}^{-2} \mathrm{day}^{-1}$ is the net long-wave surface emission and can be expressed as

$L_{\mathrm{n}}=-f \varepsilon \sigma\left(T_{\mathrm{a}}+273.2\right)^{4}$

where $f$ is the adjustment for cloud cover, derived from

$f=0.9 \frac{n}{N}+0.1$.

The $\varepsilon$ is the net emissivity, which is given by

$\varepsilon=0.34-0.14 \cdot \sqrt{e}$. 
The $\sigma$ is the Stefan-Boltzmann constant $\left(4.903 \times 10^{-9}\right.$ $\mathrm{MJ} \mathrm{m}^{-2} \mathrm{~K}^{-4}$ ) and the net radiation $R_{\mathrm{n}}$ in $\mathrm{MJ} \mathrm{m}^{-2}$ day $^{-1} \mathrm{fi}-$ nally is

$R_{\mathrm{n}}=S_{\mathrm{n}}+L_{\mathrm{n}}$.

\section{Appendix B: PET models}

\section{B1 Penman open water evaporation (PEN)}

As the basis for most preferred methods for estimating evaporation the Penman equation was introduced in 1948 (Penman, 1948) considering moisture availability, mass transfer and required energy (Abtew and Melesse, 2013b). Here, we use the implementation of the Penman equation for open water after Shuttleworth (1993), which can be expressed in $\mathrm{mm} \mathrm{d}^{-1}$ as

$\mathrm{PEN}=F_{1} \cdot A+F_{2} \cdot D$,

where $F_{1}$ is a function of temperature and the elevation of the site:

$F_{1}=\frac{\Delta}{\Delta+\gamma}$,

where $\Delta$ is the gradient of the function $\mathrm{d} e_{\mathrm{S}} / \mathrm{d} T$ in $\mathrm{kPa}^{\circ} \mathrm{C}^{-1}$ (Eq. A7) and $\gamma$ is the psychrometric constant in $\mathrm{kPa}^{\circ} \mathrm{C}^{-1}$ (Eq. A11). $F_{2}$ is a function of temperature, wind speed and the elevation of the site:

$F_{2}=\frac{\gamma}{\Delta+\gamma} \frac{6.43(1+0.536 \cdot v)}{\lambda}$,

where $v$ is wind speed in $\mathrm{m} \mathrm{s}^{-1}$ and $\lambda$ is latent heat in $\mathrm{MJ} \mathrm{kg}^{-1}$ (Eq. A10). $A$ is the energy available for evaporation given by

$A=R_{\mathrm{n}}+A_{\mathrm{h}}$,

where $R_{\mathrm{n}}$ is net radiation in $\mathrm{MJ} \mathrm{m}^{-2} \mathrm{day}^{-1}$ (Eq. A18) and $A_{\mathrm{h}}$ is the energy advected to the water body by water inflow and outflow if significant. After Shuttleworth (1993) $A=R_{\mathrm{n}}$ if no data for $A_{\mathrm{h}}$ are available, which is the case for our study site. $D$ is the saturated vapour pressure deficit, calculated with Eq. (A9).

\section{B2 Penman-Monteith combination equation (PMO)}

The Penman-Monteith equation is the most physically based model and corresponds to the Penman equation with additionally an aerodynamic surface resistance term. It is expressed as (Allen et al., 1998)

$\mathrm{PMO}=\frac{1}{\lambda} \frac{\Delta\left(R_{\mathrm{n}}-G\right)+\rho_{\mathrm{a}} c_{\mathrm{p}}\left(e_{\mathrm{s}}-e\right)}{\Delta+\gamma\left(1+\frac{r_{\mathrm{s}}}{r_{\mathrm{a}}}\right)}$, where $G$ is the soil heat flux, which can usually be neglected in the tropics (De Bruin, 1983), $\rho_{\mathrm{a}}$ is the mean air density at constant pressure in $\mathrm{kg} \mathrm{m}^{-3}, c_{\mathrm{p}}$ is the specific heat of the air in $\mathrm{MJ} \mathrm{kg}^{-1}{ }^{\circ} \mathrm{C}^{-1}, e_{\mathrm{S}}$ is the saturated vapour pressure in $\mathrm{kPa}$ (Eq. A6), $e$ is the vapour pressure at given $\mathrm{RH}$ in $\mathrm{kPa}$ (Eq. A8), $r_{\mathrm{s}}$ is the surface resistance in $\mathrm{s} \mathrm{m}^{-1}$ and $r_{\mathrm{a}}$ is the aerodynamic resistance in $\mathrm{s} \mathrm{m}^{-1}$. The $r_{\mathrm{s}}$ in the case of open water is 0 and $r_{\mathrm{a}}$ is calculated after Thom and Oliver (1977) by

$r_{\mathrm{a}}=\frac{4.72 \ln \left(\frac{2}{z_{\mathrm{o}}}\right)}{1+0.54 v}$,

where $z_{0}$ is the roughness length, which was set to $z_{\mathrm{o}}=$ $1.37 \mathrm{~mm}$ (De Bruin, 1983).

\section{B3 Priestley-Taylor equation (PRT)}

The Priestley-Taylor model (Xu and Singh, 2000, after Priestley and Taylor, 1972) is a simplified version of the Penman equation. It is assumed that the surface area is wet and therefore the atmosphere is saturated. Thus, the Priestley-Taylor coefficient $\alpha_{\mathrm{PRT}}$ is introduced, which is multiplied by the energy component:

$\mathrm{PRT}=\alpha_{\mathrm{PRT}} \frac{\Delta}{\Delta+\gamma} \frac{R_{\mathrm{n}}}{\lambda}$,

where $\alpha_{\text {PRT }}$ was set to 1.18 after Abtew and Obeysekera (1995).

\section{B4 Hargreaves equation (HAR)}

The Hargreaves equation (Xu and Singh, 2000, after Hargreaves, 1975) was derived from lysimeter data in California and can be expressed as

$\mathrm{HAR}=0.0135\left(T_{\mathrm{a}}+17.8\right) R_{\mathrm{S}}$,

where $T_{\mathrm{a}}$ and $R_{\mathrm{S}}$ have the same meaning as given before.

\section{B5 Modified Makkink equation (MAK)}

For tropical South Florida the Makkink equation (Abtew and Melesse, 2013b, after Makkink, 1957) was calibrated to the simple Abtew method (Eq. B10) and has the following form:

MAK $=0.743 \frac{\Delta S_{\mathrm{t}}}{(\Delta+\gamma) \lambda}$,

where $S_{\mathrm{t}}$ is the solar radiation in $\mathrm{MJ} \mathrm{m}^{-2}$ day $^{-1}$ (Eq. A13).

\section{B6 Simple Abtew equation (ABT)}

The simple Abtew equation (Abtew and Melesse, 2013a) was developed for tropical South Florida from open water evaporation and wetland lysimeter studies. It can be expressed as

$\mathrm{ABT}=K_{1} \frac{S_{\mathrm{t}}}{\lambda}$,

where $K_{1}$ is a dimensionless coefficient given with 0.53 . 


\section{B7 Modified Turc equation (TUR)}

We use the empirical Turc equation modified for a humid subtropical region in Florida (Abtew and Melesse, 2013b). $T_{\max }$ is used instead of $T_{\mathrm{a}}$ since it showed a better fit with observed data. The modified Turc equation is written as

$\mathrm{TUR}=K_{2} \frac{\left(23.89 S_{\mathrm{t}}+50\right) T_{\max }}{T_{\max }+15}$,

where the coefficient $K_{2}$ has the value 0.013 derived from the original Turc equation (Abtew and Melesse, 2013a).

\section{Appendix C: Input data of PET models}

Table C1. Absolute values as well as daily means of meteorological input parameter (daily means of study period have ranges due to three meteorological stations).

\begin{tabular}{|c|c|c|c|c|c|c|}
\hline \multirow[t]{2}{*}{ Parameter } & \multicolumn{2}{|c|}{$\begin{array}{l}\text { Ranking period: } \\
\text { Data used to evaluate PET } \\
\text { model performance } \\
\text { (February 2010-April 2013) }\end{array}$} & \multicolumn{2}{|c|}{$\begin{array}{c}\text { Calibration period: } \\
\text { Data used to calibrate and } \\
\text { evaluate the reduction of PET to } \\
\text { AET (26 January-10 December 2007) }\end{array}$} & \multicolumn{2}{|c|}{$\begin{array}{c}\text { Study period: } \\
\text { Data used to apply our model } \\
\text { to different locations } \\
\text { (28 April 2012-27 April 2013) }\end{array}$} \\
\hline & Absolute values & Daily mean & Absolute values & Daily mean & Absolute values & Daily mean \\
\hline$T_{\mathrm{a}}\left[{ }^{\circ} \mathrm{C}\right]$ & $10.7-32.1$ & 25.0 & $11.6-32.0$ & 25.9 & $12.3-32.7$ & $24.8-25.5$ \\
\hline$T_{\min }\left[{ }^{\circ} \mathrm{C}\right]$ & $2.6-32.1$ & 19.7 & $10.0-26.8$ & 21.0 & $0.0-32.1$ & $19.0-21.2$ \\
\hline$T_{\max }\left[{ }^{\circ} \mathrm{C}\right]$ & $11.4-36.0$ & 28.0 & $13.4-39.2$ & 31.6 & $15.9-44.0$ & $32.1-32.8$ \\
\hline RH [\%] & $47.3-93.5$ & 23.1 & 28.9-94.3 & 70.5 & $47.5-95.1$ & $72.7-79.3$ \\
\hline$v\left[\mathrm{~m} \mathrm{~s}^{-1}\right]$ & $0.13-2.03$ & 0.3 & $0.98-3.48$ & 2.0 & $0.13-7.95$ & $0.3-0.8$ \\
\hline$P_{\mathrm{a}}[\mathrm{hPa}]$ & 98.9-101.1 & 99.70 & - & 99.87 & $97.3-100.9$ & $99.74-99.76$ \\
\hline
\end{tabular}


Acknowledgements. The authors are grateful to the RPPN SESC Pantanal for transport, accommodation and field assistance in the framework of the Long Term Ecological Research project with funding through the Brazilian National Science and Technology Research Council (Conselho Nacional de Desenvolvimento Científico e Tecnológico - $C N P q$ ). Field study was enabled by the help of "guarda-parques" and "brigadistas" from the RPPN SESC Pantanal. Especially, we like to thank Guarda-Parques Rodrigo and Pedro Paulo for their effort in helping to install our water level probes. Meteorological data have been collected from the Brazilian National Research Institute for Humid Areas (Instituto Nacional de Áreas Úmidas - INAU). The first author is funded by the IPSWaT (International Postgraduate Studies in Water Technology) PhD scholarship of the German Federal Ministry of Education and Research (BMBF). The article processing charge was funded by the open access publication fund of the Albert Ludwigs University Freiburg.

\section{Edited by: J. Liu}

\section{References}

Abtew, W. and Obeysekera, L.: Lysimeter study of evapotranspiration of cattails and comparison of three estimation methods, 1, Am. Soc. Agr. Eng., 38, 121-129, 1995.

Abtew, W.: Evapotranspiration measurements and modeling for three wetland systems in South Florida, J. Am. Water Resour. As., 32, 465-473, doi:10.1111/j.1752-1688.1996.tb04044.x, 1996.

Abtew, W.: Evapotranspiration in the Everglades: Comparison of Bowen Ratio measurements and model estimations, Technical Paper EMA \#417, ASAE Meeting, Tampa, 2004.

Abtew, W., Obeysekera, J., and Iricanin, N.: Pan evaporation and potential evapotranspiration trends in South Florida, Hydrol. Process., 25, 958-969, doi:10.1002/hyp.7887, 2011.

Abtew, W. and Melesse, A.: Wetland evapotranspiration, in: Evaporation and Evapotranspiration - Measurements and Estimations, Springer, Dordrecht, 93-108, 2013a.

Abtew, W. and Melesse, A.: Evaporation and Evapotranspiration: Measurements and Estimations, Spinger Science + Business Media, Dordrecht, 2013b.

Alho, C. J. R.: Biodiversity of the Pantanal: Response to seasonal flooding regime and to environmental degradation, Braz. J. Biol., 68, 957-966, doi:10.1590/s1519-69842008000500005, 2008.

Allen, R. G., Pereira, L. S., Raes, D., and Smith, M.: Crop evapotranspiration - Guidelines for computing crop water requirements, FAO Irrigation and Drainage Paper 56, 1998.

Bautista, F., Bautista, D., and Delgado-Carranza, C.: Calibration of the equations of Hargreaves and Thornthwaite to estimate the potential evapotranspiration in semi-arid and subhumid tropical climates for regional applications, Atmósfera, 22, 331-348, 2009.

Biudes, M. S., Campelo Júnior, J. H., Nogueira, J. S., and Sanches, L.: Estimativa do balanço de energia em cambarazal e pastagem no norte do Pantanal pelo método da razão de Bowen, Revista Brasileira de Meteorologia, 24, 56-64, 2009.

Bruland, G. L., Grunwald, S., Osborne, T. Z., Reddy, K. R., and Newman, S.: Spatial Distribution of Soil Properties in Water Conservation Area 3 of the Everglades, Soil Sci. Soc. Am. J., 70, 1662-1676, doi:10.2136/sssaj2005.0134, 2006.
Brutsaert, W. and Chen, D.: Desorption and the two Stages of Drying of Natural Tallgrass Prairie, Water Resour. Res., 31, 1305-1313, doi:10.1029/95wr00323, 1995.

Brutsaert, W.: Hydrology - An Introduction, Cambridge University Press, Cambridge, 2005.

Burba, G. G., Verma, S. B., and Kim, J.: Surface energy fluxes of Phragmites australis in a prairie wetland, Agr. Forest Meteorol., 94, 31-51, 1999.

Canadell, J., Jackson, R. B., Ehleringer, J. R., Mooney, H. A., Sala, O. E., and Schulze, E.-D.: Maximum rooting depth of vegetation types at the global scale, Oecologia, 108, 583-595, 1996.

Couto, E. G. and De Oliveira, V. A.: The soil diversity of the Pantanal, in: The Pantanal of Mato Grosso: Ecology, biodiversity and sustainable management of a large neotropical seasonal wetland, Pensoft Publishers, Sofia, 40-64, 2008.

Cuenca, R. H.: Irrigation system design: an engineering approach, Englewood Cliffs, N.J., Prentice Hall, 1989.

De Bruin, H. A. R.: Evapotranspiration in humid tropical regions, Hydrology of Humid Tropical Regions with Particular Reference to the Hydrological Effects of Agriculture and Forestry Practice, Proceedings of the Hamburg Symposium, IAHS Publ. no. 140, Hamburg, 1983.

Delclaux, F., Coudrain, A., and Condom, T.: Evaporation estimation on Lake Titicaca: a synthesis review and modelling, Hydrol. Process., 21, 1664-1677, doi:10.1002/hyp.6360, 2007.

Doorenbos, J. and Pruitt, W. O.: Guidelines for predicting crop water requirements, FAO Irrigation and Drainage Paper 24, 1977.

Drexler, J. Z., Snyder, R. L., Spano, D., and Paw U, K. T.: A review of models and micrometeorological methods used to estimate wetland evapotranspiration, Hydrol. Process., 18, 2071-2101, doi:10.1002/hyp.1462, 2004.

German, E. R.: Regional Evaluation of Evapotranspiration in the Everglades, US Geological Survey, Water Resources Investigations Report 00-4217, 2000.

Girard, P.: Efeito cumulativo das barragens no Pantanal, Instituto Centro Vida, Campo Grande, Mato Grosso do Sul, 2002.

Girard, P.: Hydrology of surface and groundwaters in the Pantanal floodplains, in: The Pantanal: Ecology, biodiversity and sustainable management of a large neotropical seasonal wetland, Pensoft Publishers, Sofia, 103-126, 2011.

Glover, J. and McCulloch, J. S. G.: The empirical relation between solar radiation and hours of sunshine, Q. J. Roy. Meteor. Soc., 84, 172-175, doi:10.1002/qj.49708436011, 1958.

Gonçalves, H. C., Mercante, M. A., and Santos, E. T.: Hydrological cycle, Braz. J. Biol., 71, 241-253, 2011.

Harbaugh, A. W.: MODFLOW-2005, The U.S. Geological Survey Modular Ground-Water Model - the Ground-Water Flow Process, US Geological Survey Techniques and Methods 6-A16, 2005.

Hargreaves, G. H.: Moisture availability and crop production, Trans. ASAE, 18, 980-984, 1975.

Hasenack, H., Passos Cordeiro, J. L., and Selbach Hofmann, G.: O clima da RPPN SESC Pantanal, Relatório técnico, Universidade Federal do Rio Grande do Sul, Instituto de Biosciéncias, Centro de Ecologia, 2003.

Heckman, C. W.: The Pantanal of Poconé: Biota and ecology in the northern section of the world's largest pristine wetland, Kluwer Academic Publishers, Dordrecht, Boston, London, 1998. 
Hill, A. J. and Neary, V. S.: Estimating evapotranspiration and seepage for a sinkhole wetland from diel surface-water cycles, J. Am. Water Resour. As., 43, 1373-1382, 2007.

Idso, S. B., Reginato, R. J., Jackson, R. D., Kimball, B. A., and Nakayama, F. S.: The Three Stages of Drying of a Field Soil, Soil Sci. Soc. Am. J., 38, 831-837, doi:10.2136/sssaj1974.03615995003800050037x, 1974.

Idso, S. B.: Relative rates of evaporative water losses from open and vegetation covered water bodies, J. Am. Water Resour. As., 17, 46-48, doi:10.1111/j.1752-1688.1981.tb02587.x, 1981.

Irion, G., Buchas, H., Junk, J. W., Nunes Da Cunha, C., De Morais, J. O., and Kasbohm, J.: Aspects of geological and sedimentological evolution of the Pantanal plain, in: The Pantanal: Ecology, biodiversity and sustainable management of a large neotropical seasonal wetland, Sofia, 47-70, 2011.

Jacobs, J. M., Mergelsberg, S. L., Lopera, A. F., and Myers, D. A.: Evapotranspiration from a wet prairie wetland under drought conditions: Paynes prairie preserve, Florida, USA, Wetlands, 22, 374-385, doi:10.1672/02775212(2002)022[0374:efawpw]2.0.co;2, 2002.

Johnson, M. S., Couto, E. G., Pinto Junior, O. B., Milesi, J., Amorim, R. S. S., Messias, I. A. M., and Biudes, M. S.: Soil $\mathrm{CO}_{2}$ Dynamics in a Tree Island Soil of the Pantanal: The Role of Soil Water Potential, PLOS ONE, 8, e64874, doi:10.1371/journal.pone.0064874, 2013.

Krause, P., Boyle, D. P., and Bäse, F.: Comparison of different efficiency criteria for hydrological model assessment, Adv. Geosci., 5, 89-97, doi:10.5194/adgeo-5-89-2005, 2005.

Kottek, M., Grieser, J., Beck, C., Rudolf, B., and Rubel, F.: World map of the Köppen-Geiger climate classification updated, Meteorologische Z., 15, 259-263, doi:10.1127/0941-2948/2006/0130, 2006.

Legates, D. R. and McCabe, G. J.: Evaluating the use of "goodness-of-fit" Measures in hydrologic and hydroclimatic model validation, Water Resour. Res., 35, 233-241, doi:10.1029/1998wr900018, 1999.

Luo, Y. F., Peng, S. Z., Khan, S., Cui, Y. L., Wang, Y., and Feng, Y. H.: A comparative study of groundwater evapotranspiration functions, 18th World Imacs Congress and Modsim09 International Congress on Modelling and Simulation: Interfacing Modelling and Simulation with Mathematical and Computational Sciences, Univ Western Australia, Nedlands, 3095-3101, 2009.

Makkink, G. F.: Testing the Penman formula by means of lysimeters, J. Institution of Water Eng., 11, 277-288, 1957.

Mao, L. M., Bergman, M. J., and Tai, C. C.: Evapotranspiration measurement and estimation of three wetland environments in the upper St. Johns river basin, Florida, J. Am. Water Resour. As., 38, 1271-1285, doi:10.1111/j.1752-1688.2002.tb04347.x, 2002.

Martínez-Lozano, J. A., Tena, F., Onrubia, J. E., and De La Rubia, J.: The historical evolution of the Ångström formula and its modifications: Review and bibliography, Agr. Forest Meteorol., 33, 109-128, doi:10.1016/0168-1923(84)90064-9, 1984.

McJannet, D. L., Webster, I. T., Stenson, M. P., and Sherman, B. S.: Estimating open water evaporation for the Murray-Darling Basin, A report to the Australian Government from the CSIRO Murray-Darling Basin Sustainable Yields Project, 2008.
McLaughlin, D. L. and Cohen, M. J.: Ecosystem specific yield for estimating evapotranspiration and groundwater exchange from diel surface water variation, Hydrol. Process. 28, 495-1506, 2014

McMahon, T. A., Peel, M. C., Lowe, L., Srikanthan, R., and McVicar, T. R.: Estimating actual, potential, reference crop and pan evaporation using standard meteorological data: a pragmatic synthesis, Hydrol. Earth Syst. Sci., 17, 1331-1363, doi:10.5194/hess-17-1331-2013, 2013.

Melesse, A., Abtew, W., and Dessalegne, T.: Evaporation Estimation of Rift Valley Lakes: Comparison of Models, Sensors, 9, 9603-9615, 2009.

Mesquita, F. L. L., Filho, E. P. M., de Souza, R. L. M., and Karam, H. A.: Surface energy budget over the Pantanal wetland during the dry season, VI Workshop Brasileiro de Micrometeorologia, Santa Maria, 97-100, 2009.

Mohamed, Y. A., Bastiaanssen, W. G. M., Savenije, H. H. G., van den Hurk, B. J. J. M., and Finlayson, C. M.: Wetland versus open water evaporation: An analysis and literature review, Phys. Chem. Earth, 47-48, 114-121, doi:10.1016/j.pce.2011.08.005, 2012.

Orang, M.: Potential accuracy of the popular non-linear regression equations for estimating pan coefficient values in the original and FAO-24 tables, Unpublished rep., California Department of Water Resources, Sacramento, 68, 1998.

Penman, H. L.: Natural Evaporation from Open Water, Bare Soil and Grass, Proc. Royal Soc. London. Series A, 193, 120-145, doi:10.1098/rspa.1948.0037, 1948.

Ponce, V. M.: Hydrologic and environmental impact of the ParanáParaguay Waterway on the Pantanal of Mato Grosso, Brazil: A Reference Study, San Diego State University, California, 1995.

Por, F. D.: The Pantanal of Mato Grosso (Brazil), World's largest wetlands, Kluwer Academic Publishers, Dordrecht, Boston, London, 1995.

Priestley, C. H. B. and Taylor, R. J.: On the Assessment of Surface Heat Flux and Evaporation Using Large-Scale Parameters, Mon. Weather Rev., 100, 81-92, doi:10.1175/15200493(1972)100<0081:otaosh>2.3.co;2, 1972.

Ramsar Convention on Wetlands, available at: www.ramsar.org, last access: 7 July 2011

Saghravani, S. R., Mustapha, S., Ibrahim, S., and Randjbaran, E.: Comparison of Daily and Monthly Results of Three Evapotranspiration Models in Tropical Zone: A Case Study, Am. J. Environ. Sci., 5, 698-705, 2009.

Sanches, L., Alves, M. C., Campelo, J. H., Nogueira, J. S., and Dalmagro, H. J.: Estimativa do coeficiente Pristely-Taylor em floresta monodominante Cambarazal no Pantanal, Revista Brasileira de Meteorologia, 25, 448-445, 2010.

Sanches, L., Vourlitis, G. L., Carvalho Alves, M., Pinto-Júnior, O. B., and Souza Nogueira, J.: Seasonal Patterns of Evapotranspiration for a Vochysia divergens Forest in the Brazilian Pantanal, Wetlands, 31, 1215-1225, doi:10.1007/s13157-011-02330,2011 .

Schenk, H. J. and Jackson, R. B.: The global biogeography of roots, Ecol. Monogr., 72, 311-328, doi:10.1890/00129615(2002)072[0311:tgbor]2.0.co;2, 2002. 
Schwerdtfeger, J., Weiler, M., Johnson, M. S., and Couto, E. G.: Estimating Water Balance Components of Tropical Wetland Lakes in the Pantanal Dry Season, Brazil, Hydrol. Sci. J., 59, 2158-2172, doi:10.1080/02626667.2013.870665, 2013.

Shoemaker, W. B. and Sumner, D. M.: Alternate corrections for estimating actual wetland evapotranspiration from potential evapotranspiration, Wetlands, 26, 528-543, doi:10.1672/02775212(2006)26[528:acfeaw]2.0.co;2, 2006.

Shuttleworth, W. J.: Evaporation, in: Handbook of Hydrology, McGraw-Hill, New York, USA, 1993.

Silva, C. J. and Girard, P.: New challenges in the management of the Brazilian Pantanal and catchment area, Wetl. Ecol. Manag., 12, 553-561, doi:10.1007/s11273-005-1755-0, 2004.

Souch, C., Susan, C., Grimmond, B., and Wolfe, C.: Evapotranspiration rates from wetlands with different disturbance histories: Indiana Dunes National Lakeshore, Wetlands, 18, 216-229, doi:10.1007/bf03161657, 1998.

Stoll, S. and Weiler, M.: Explicit simulations of stream networks to guide hydrological modelling in ungauged basins, Hydrol. Earth Syst. Sci., 14, 1435-1448, doi:10.5194/hess-14-14352010, 2010.

Sumner D. M.: Effects of capillarity and microtopography on wetland specific yield, Wetlands, 27, 693-701, 2007

Tamea, S., Muneepeerakul, R., Laio, F., Ridolfi, L., and Rodriguez-Iturbe, I.: Stochastic Description of Water Table Fluctuations in Wetlands, Geophys. Res. Lett., 37, L06403, doi:10.1029/2009GL041633, 2010.

Tanner, C. B.: Energy balance approach to evapotranspiration from crops, Soil Sci. Soc. Am. J., 24, 1-9, 1960.

Thom, A. S. and Oliver, H. R.: On Penman's equation for estimating regional evaporation, Q. J. Roy. Meteor. Soc., 103, 345-357, 1977.
Vardavas, I. M. and Fountoulakis, A.: Estimation of lake evaporation from standard meteorological measurements: application to four Australian lakes in different climatic regions, Ecol. Model., 84, 139-150, doi:10.1016/0304-3800(94)00126-X, 1996.

Vourlitis, G. L., Filho, N. P., Hayashi, M. M. S., de S. Nogueira, J., Caseiro, F. T., and Campelo, J. H.: Seasonal variations in the evapotranspiration of a transitional tropical forest of Mato Grosso, Brazil, Water Resour. Res., 38, 30-1-30-11, doi:10.1029/2000wr000122, 2002.

Wang, K. and Dickinson, R. E.: A review of global terrestrial evapotranspiration: Observation, modeling, climatology, and climatic variability, Rev. Geophys., 50, 1-54, doi:10.1029/2011rg000373, 2012.

Wantzen, K. M., Da Cunha, C. N., Junk, W. J., Girard, P., Rossetto, O. C., Penha, J. M., Couto, E. G., Becker, M., Priante, G., Tomas, W. M., Santos, S. A., Marta, J., Domingos, I., Sonoda, F., Curvo, M., and Callil, C.: Towards a sustainable management concept for ecosystem services of the Pantanal wetland, Ecohydrol. Hydrobiol., 8, 115-138, doi:10.2478/v10104-009-0009-9, 2008.

Watanabe, K., Yamamoto, T., Yamada, T., Sakuratani, T., Nawata, E., Noichana, C., Sributta, A., and Higuchi, H.: Changes in seasonal evapotranspiration, soil water content, and crop coefficients in sugarcane, cassava, and maize fields in Northeast Thailand, Agr. Water Manag., 67, 133-143, doi:10.1016/j.agwat.2004.02.004, 2004.

$\mathrm{Xu}, \mathrm{C}$. Y. and Singh, V. P.: Evaluation and generalization of temperature-based methods for calculating evaporation, Hydrol. Process., 15, 305-319, doi:10.1002/hyp.119, 2000.

Zedler, J. B. and Kercher, S.: Wetland resources: Status, trends, ecosystem services, and restorability, Annu. Rev. Env. Resour., 30, 39-74, 2005. 